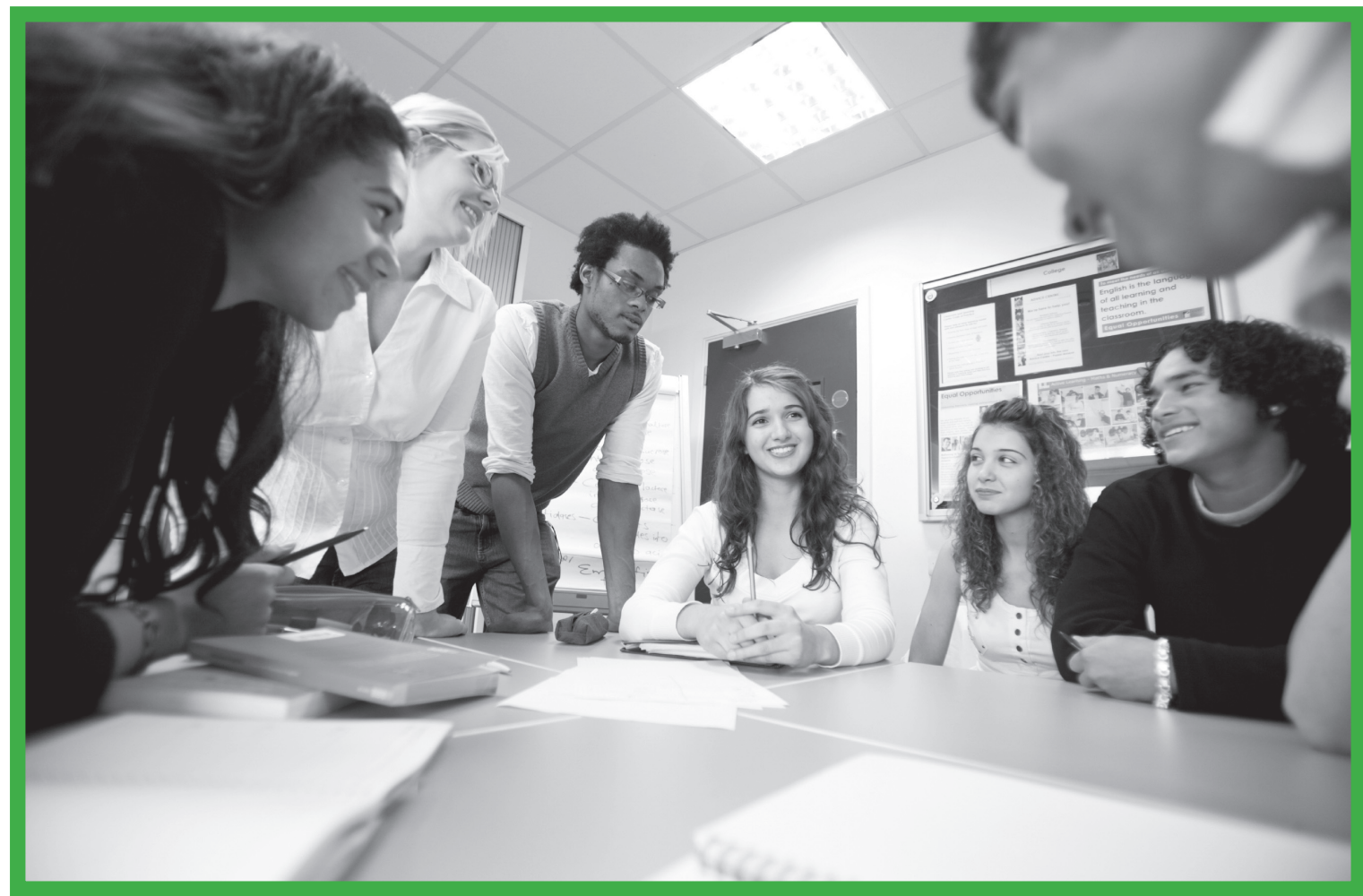

\title{
ARE YOU AN ACTION TEACHER? WIN \$1,000 WHILE MAKING THE WORLD A BETTER PLACE
}

\section{Scott Plous, PhD}

Wesleyan University

urt Lewin, a pioneering German social psychologist who escaped the Holo-

caust before it claimed his mother's life, once famously wrote, "Research that produces nothing but books will not suffice" (1948, p. 203). Instead, shortly after serving as president of the Society for the Psychological Study of Social Issues, Lewin called for action research addressing urgent societal problems such as antiSemitism, group conflict, and social injustice.

More than half a century later, Lewin's call has been answered with thousands of research reports on the psychology of prejudice, genocide, poverty, child abuse, and a host of other topics. Curiously, though, psychologists have yet to develop an equally large, coherent body of teaching materials focused on social issues.

In light of this omission, several years ago I published an article briefly describing an example of what I called "action teaching"- the pedagogical counterpart of Lewinian action research (Plous, 2000). In the example I provided, students participated in a role-playing exercise that challenged them to reduce the prejudice of a bigoted speaker by applying effective persuasion techniques. The goal of the role-playing exercise was twofold (as it is with psychology action teaching in general): to help students understand human behavior and to address important societal issues.

\section{EXAMPLES OF ACTION TEACHING}

Action teaching can involve classroom activities, field experiences, student assignments, or Internet-based demonstrations. Regardless of the approach taken, the core of action teaching is to embrace the twin goals of benefiting society as well as the individual student. Here are just a

Action Teaching, continued on page 4
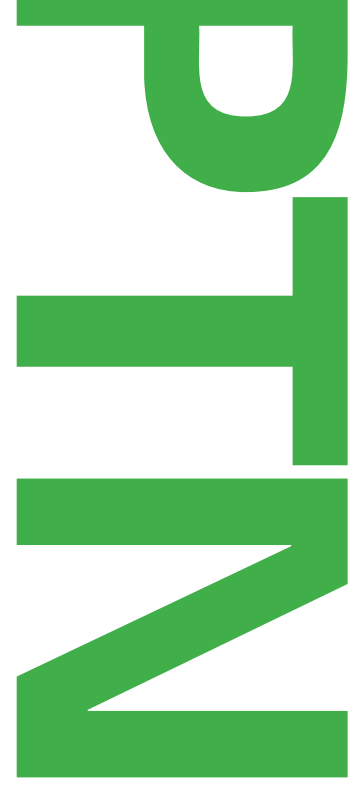

PSYCHOLOGY TEACHER NETWORK 
few innovative examples of action teaching developed in recent years:

- At Emerson College, students in a consumer psychology class learned about research methods by designing and testing their own public education campaign to encourage campus diners to make healthier food choices. In this group activity, students focused on an issue relevant to their daily lives, and to the extent that the campaign succeeded, diners were left with a healthier diet after the class had ended.

- In an empathy-building exercise at the University of Florida, students in a course on the psychology of women spent a full day either observing or role playing a woman who differed from them in age, ability status, religion, race/ ethnicity, sexual orientation, pregnancy, or motherhood. Students then wrote a paper about what it was like to live as the person they chose, and they gave a class presentation about their experience.

- After a devastating tsunami struck countries near the Indian Ocean, students at Western Washington University learned about cross-cultural responses to traumatic events and helped establish an International Tsunami Museum in Thailand. In its first week of operation, the class's museum drew more than 3,000 visitors, and over time it received so many donations that the museum was able to buy a year's supply of safe drinking water for local school children.

- The Project Implicit Web site (https://implicit.harvard.edu/ implicit/), maintained at Harvard University and modeled after an interactive museum exhibit, has assessed millions of people for hidden biases based on race, gender, age, sexual orientation, and other social dimensions. Once an individual is assessed for bias, the Web site presents personalized feedback along with information about how to reduce implicit biases and stereotypes.

\section{THE BENEFITS OF ACTION TEACHING}

Although some psychology instructors may feel that societal problems such as bigotry, food choices, and natural disasters are irrelevant to the courses they teach, societal problems can play an indispensable role in psychology training. In my view, action teaching offers a way to make course material more relevant to students, and it represents a unique learning opportunity that students often rate as the most valuable part of a course.

For instance, when I asked students to rate the value of the prejudice reduction exercise mentioned earlier, they gave it a modal rating of 9 on a 9-point scale, and all students recommended using the exercise with future classes. As one student wrote on the anonymous evaluation form, "I feel like I learned a huge amount in a short period of time about being on both ends of a prejudice[d] statement."

Why is action teaching effective? First, many students already care about social issues, so enthusiasm and participation rates tend to be high. Second, action teaching typically involves active learning; thus, its lessons tend to be enduring. Third, socially engaged learning promotes bonding and cohesion among members of the class. And of course, students generally see their course work as more meaningful when it serves the greater good.

For all these reasons, action teaching constitutes a win-win method of instruction that has educational as well as societal value (Azar, 2008). Indeed, instructors who ignore social problems miss two great opportunities. Not only do they miss an opportunity to improve society-a goal that led many of us to teach in the first place-but they miss an opportunity for memorable, meaningful, high-impact teaching.

\section{WHO CAN BE AN ACTION TEACHER?}

It's easy to see how action teaching can enhance courses that already cover social or political issues, but what about other courses? Can action teaching be used across the curriculum in psychology? I believe the answer is yes; virtually any instructor can be an action teacher, including instructors who teach introductory psychology, research methods, statistics, and a wide variety of topical areas. To take just one example-the environment-here's how action teachers might address a topic that many students care deeply about:

Introductory psychology. Action teachers might give a lecture on the link between human behavior and climate change, challenge students to reduce their carbon footprint for a week, and ask them to write a paper analyzing the experience. Especially interesting or worthwhile ideas might then be shared with the class. (Note: Action teaching is especially easy to employ in introductory psychology courses because so many topics apply to daily life. For a compilation, see http://psychologymatters.apa.org/.)

Research methods. Action teachers might assign group projects in which class members design and implement a local environmental initiative, measure its effect (e.g., in terms of reduced energy consumption, water usage, or disposable waste), analyze the results, and present their conclusions to the class. 
Statistics. Action teachers might use government climate change data or other environmental information in classroom lectures and student problem sets. Students learning about regression, for example, might be interested to discover that research on heat and aggression predicts an annual increase of more than 12,000 murders and assaults in the United States for each $1^{\circ} \mathrm{F}$ rise in average temperature (Anderson, 2001).

Courses on decision making. Action teachers might explain how problem framing influences the choices people make and might ask students to develop environmentally friendly ways of framing product choices. Researchers have found, for instance, that people make more fuel-efficient choices when gas mileage is framed in terms of gallons per 100 miles driven than in miles per gallon (Larrick \& Soll, 2008).

\section{Courses on marketing and consumer research.}

Action teachers might discuss social marketing (i.e., the application of marketing techniques to create prosocial changes in behavior) and have the class develop a Webbased social marketing campaign to reduce climate change. This campaign might include streaming video messages, blogging, social networking, or other paperless forms of mass communication.

\section{If action teachers want to have a wide impact on society, perhaps the single best use of time is to share their work with other instructors.}

Turning to topics other than environmentalism, courses covering persuasion might invite students to increase voter registration, racial integration on campus, or other social goods defined by the students themselves. Courses in neuroscience might offer action teaching assignments in neuroeconomics, neurolaw, or related fields at the intersection of science and society. Courses in personality psychology, developmental psychology, or conflict resolution might discuss the societal benefits of empathy and challenge students to devise interventions to increase it. In sum, the possibilities for action teaching are as broad as the number of issues facing society.

\section{TIPS ON IMPLEMENTATION}

Good teaching is grounded in respect for students, and action teaching is no exception. With that principle in mind, let me offer three tips for implementing effective action teaching.

First, action teaching should be pedagogical, not partisan. That is, instructors should never use their teaching position or the students in their classes simply to advance a political agenda. If an instructor has any doubt about where the line between pedagogy and partisanship is, my advice would be to consult a dean, departmental chairperson, or other senior colleagues.

Second, to avoid coercion, I recommend giving students the chance to opt out of any action teaching assignment or course activity that they prefer not to do (in fact, an "opt out" clause is something I use whether or not a lesson involves action teaching). To take an example, here is what my introductory social psychology syllabus says about a series of small assignments:

\section{If at any point you prefer not to complete an assignment (or if your attempt to complete it is unsuccessful), you can still receive full credit by turning in a one-page report discussing the barriers that prevented you from carrying out the assignment.}

In those rare cases when students opt out, they invariably appreciate the freedom to do so and seldom opt out of anything else in the course.

Third, I suggest assessing the effectiveness of action teaching techniques whenever possible, including the solicitation of anonymous feedback from students. This emphasis on assessment is consistent with Lewin's approach to action research in which "action ... is always followed by self-critical objective reconnaissance and evaluation of results" (Marrow, 1969, p. 193).

\section{THE IMPORTANCE OF DISSEMINATION}

Because a key goal of action teaching is to have a positive impact on society, it is just as important to disseminate good action teaching practices as it is to develop them for one's own students. Efforts at dissemination include posting lesson plans and teaching materials on the Web; distributing them via listservs and social networks; publishing them in professional journals, magazines, and newsletters; and 
sharing them at meetings and workshops. In every case, these activities serve as "value multipliers" by putting action teaching materials into the hands of other instructors.

Indeed, action teachers who devote just one tenth of their teaching time to dissemination-and whose ideas are adopted by just 10 other instructors as a result-have roughly 100 -fold more societal impact per time spent disseminating ideas than when employing them in their own teaching. That is, if action teachers want to have a wide impact on society, perhaps the single best use of time is to share their work with other instructors.

\section{HOW TO WIN \$1,000}

As executive director of the Social Psychology Network (SPN), I am often contacted by instructors looking for action teaching materials, and in response l've posted a number of materials on two SPN Web sites:

\section{www.SocialPsychology.org www.UnderstandingPrejudice.org}

Most action teaching pages posted on the first site have by now received $30,000-50,000$ visits, and several action teaching pages on the second site have likewise received thousands of visits.

Emboldened by this high level of interest, I established an annual SPN Action Teaching Award in 2005. The award comes with a $\$ 1,000$ cash prize, and entries that pass an initial screening are blind reviewed by a panel of teaching experts. Eligible entries include classroom activities, student assignments, field experiences, or Web-based tutorials and demonstrations (the four action teaching examples summarized on page 4 of this article either won the award or received honorable mention).

Best of all, anyone submitting an entry agrees to let SPN post an edited version on the Web for other instructors to use freely or adapt (with appropriate citation). In this way, the award not only honors and encourages innovative teaching but also builds a database of award-winning materials for use by the broader teaching community. Since the first winning entries were posted on the Web in 2006, these pages have collectively received over 30,000 visits.

\section{CONCLUSION}

I hope readers will address the urgent need for action teaching with the same creativity and passion that has marked Lewinian action research, and that they will share the fruits of their labor with others.
To facilitate the development and exchange of effective action teaching materials, I invite readers to submit entries for the next SPN Action Teaching Award. For details, including deadline information and a compendium of previous winners, please visit:

\section{www.ActionTeaching.org}

\section{REFERENCES}

Anderson, C. A. (2001). Heat and violence. Current Directions in Psychological Science, 10, 33-38.

Azar, B. (2008, December). Bringing lessons to life. Monitor on Psychology, 39, 56-58. (For a free copy, visit www.socialpsychology.org/pdf/action-teaching.pdf)

Larrick, R. P., \& Soll, J. B. (2008, June). The MPG illusion. Science, 320(5883), 1593-1594.

(See also www.mpgillusion.com/ and www.socialpsychology.org/action/2009honor3.htm)

Lewin, K. (1948). Resolving social conflicts: Selected papers on group dynamics. New York: Harper.

Marrow, A. J. (1969). The practical theorist: The life and work of Kurt Lewin. New York: Basic Books.

Plous, S. (2000). Responding to overt displays of prejudice: A role-playing exercise. Teaching of Psychology, 27, 198-200. (For a free copy, visit www.understandingprejudice.org/pdf/roleplay.pdf) PTN 


\section{ACTION TEACHING ASSIGNMENTS}

Here are a few student assignments that capture the spirit of action teaching. Readers are welcome to use or adapt these assignments for their own teaching purposes.

\section{The Day of Compassion}

Description: This assignment challenges students to spend a full day living as compassionately as possible and then asks them to write a brief report analyzing the experience.

Note: Since the 1990s, I have given this assignment to more than 1,500 students. Most students find it to be very engaging, and some describe it as life changing. The assignment can be used to teach about empathy, prosocial behavior, bystander intervention, conflict resolution, and participant-observation research methods, among other topics.

Social value: As a result of this assignment, students have reconciled with estranged parents, mediated family disputes, helped friends and strangers in need, visited nursing home residents, contributed time or money to social causes, made micro-loans to people in developing nations, and carried out hundreds of other acts of kindness.

www.socialpsychology.org/teach/compassion.htm

\section{Internet-Based Persuasion Assignment}

Description: This assignment asks students to visit the anti-tobacco JoeChemo.org Web site, take a 10-item "Tobacco IQ Test," get a personalized Smoke-o-Scope predicting their future health, and explore the site's other features. Students are then asked to submit a report discussing the Web site's strengths and weaknesses in persuading people not to smoke.

Note: The assignment can be used to teach about persuasion, social influence, behavior change, health psychology, advertising, and many other topics. For example, students studying persuasion might discuss how the Web site employs central and peripheral routes to persuasion, fear appeals, source credibility, the poison parasite defense, normative influence, and other attitude change techniques.
Social value: After completing this assignment, students often report a strengthening of anti-tobacco attitudes or, if they smoke, a desire to quit smoking. In addition, many students report sharing the site with friends or family members in an effort to protect the health of others.

www.socialpsychology.org/teach/chemo.htm

\section{The Diet \& Lifestyle Choices Interview}

Description: This assignment invites students to take the Diet \& Lifestyle Choices Interview, a Web-based interview capable of changing questions, response options, and item wordings depending on the previous answers given. After taking the interview, students write a paper comparing the experience with a traditional face-to-face interview.

Note: The interview used in this assignment is part of an ongoing research project on personal and moral decision making, so it offers a chance for students to see firsthand how advances in technology are opening up new ways to study complex social issues. The assignment can be used to teach about research methods, moral judgment and decision making, attitude measurement, interviewing, and other assorted topics.

Social value: When taking the interview, many students discover instances in which their lifestyle choices conflict with values that they hold (e.g., students with a meatintensive diet may come to view their diet as conflicting with their desire to reduce climate change). In such cases, these discoveries help students think more deeply about their lifestyle choices, personal values, and beliefs about sustainable living.

www.socialpsychology.org/teach/lifestyle.htm

For dozens of other student assignments, classroom activities, and related resources on action teaching, please see:

- SPN Action Teaching Award http://www.actionteaching.org

- UnderstandingPrejudice.org Teacher's Corner http://www.understandingprejudice.org/teach/

- Institute for Humane Education http://www.humaneeducation.org/

- Teaching Tolerance

http://www.tolerance.org/ 